\title{
Level of importance attached to competitive intelligence at a mass import retail organization
}

\author{
M. Begg \\ Centre for Information and Knowledge Management \\ University of Johannesburg \\ South Africa \\ begg@worldonline.co.za \\ A.S.A. du Toit \\ Centre for Information and Knowledge Management \\ University of Johannesburg \\ South Africa \\ adutoit@uj.ac.za
}

The purpose of this research was to establish the level of importance attached to competitive intelligence (CI) at a mass import retail organization in South Africa. The rationale of CI is to alert an organization about the current situation as it relates to its business environment and competitors, and how these aspects affect the competitive situation. In this article, the value and significance that CI presents to organizations upon implementation are discussed by focusing upon the need for a competitive strategy, the significance of institutionalizing CI, various organizational structure options and the establishment of a CI culture. A survey was conducted at a mass import retail organization to determine the level of importance attached to CI. A total of 107 employees were randomly selected to participate in the completion of a questionnaire. Based on the results, it was found that this organization practised CI, albeit in an informal manner, and it was concluded that there was a relatively high level of importance attached to CI within this organization. However, areas for improvement were identified and a recommendation was made of implementing a formal CI function within the organization.

Keywords: Competitive intelligence, competitive strategy, competitive intelligence culture

Received 1 October 2007; accepted 29 October 2007

\section{Contents}

1. Introduction

2. Importance of CI for organizations 2.1 Need for a competitive strategy 
2.2 Aptitude to use CI

2.3 Ability to study competitors

3. Significance of institutionalizing CI

3.1 Anticipate changes in the marketplace

3.2 Foresee the movements of competitors

3.3 Enable effective business strategies

3.4 Learn about political or legislative regulations

3.5 Enter new business ventures

4. CI organizational structure options

4.1 Decentralized approach

4.2 Centralized approach

4.3 Hybrid approach

5. Establishing a CI culture

6. Empirical survey

6.1 Methodology

6.2 Findings

7. Recommendations

8. Conclusion

9. References

\section{Introduction}

Although it comes as no surprise that monitoring the behaviour of competitors in current times is of paramount importance, competitive intelligence (CI) as a formalized activity was only institutionalized in the USA during the 1970s and 1980s. CI alerts organizations as to what is 'unknown' and forces them to make quality decisions (Cook and Cook 2000:5). Furthermore, CI is the process of gathering information that would then be processed, analysed and disseminated to those who require intelligence. In examining CI within the context of South Africa and bearing in mind the importance of CI, it was found that numerous local heads of organizations have not received formal education or training in CI, which is disappointing to note since $\mathrm{CI}$ is vital for organizations to remain competitive and to perform well. Another area of concern in the South African context is that in the majority of organizations CI has not been implemented at all. Although there is a need for decision makers to identify the role of CI in organizations, only a limited amount of literature explains exactly how this discipline should be implemented and aligned in the organization (Havenga and Botha 2003:26-35). Viviers, Saayman and Muller (2005:576-589) note that although CI in South Africa is enjoying an increased prominence, it is not yet on the same level of countries such as the USA, Australia, Japan, France and Canada.

CI is stated by many to be one of the most important strategic management tools that has attracted much attention in many organizations across the globe. Tyson (1995:14-21) confirms that the underlying foundation of $\mathrm{CI}$ is valuable to organizations since it allows them to maintain market share in the face of strong competition, identify opportunities for growth and minimize threats. Therefore, key decision makers constantly require intelligence that may be enacted upon, thus resulting in a profoundly positive effect on an organization's market position and profitability. For CI to perform successfully within organizations, there must be clarity with regard to issues such as which intelligence products are required, establishing a CI culture within the organization and where to locate a CI unit within the organizational structure. Using this as the foundation, one would then be able to succeed in completing the CI cycle by determining the intelligence needs within the organization and then disseminating the CI products to decision makers (Hitt, Ireland and Hoskisson 2000:208). 
CI, with its huge potential benefits upon implementation, can be considered as one of the most fundamental tools of business science in contemporary times. Therefore, the following question was formulated for this research:

What is the level of importance attached to CI at a mass import retail organization in South Africa?

\section{Importance of CI for organizations}

\subsection{Need for a competitive strategy}

The need for an organization to function with a competitive strategy is influenced by the degree of intensity of competition within the market serviced by the organization. The industries that have embraced CI are those who operate in a highly turbulent and unpredictable market that changes rapidly. Such industries are the telecommunication, pharmaceutical and financial service industries. Hambrick and Fredrickson (2005:48-59) state that the competition witnessed in these industries has increased due to a series of developments that have strengthened the competition between organizations such as privatization, deregulation, liberalization, global marketing and periods of economic recession. It is therefore vital for an organization to have an integrated design for the achievement of its objectives.

West (2001:29) comments on privatization by stating that many industries, such as the electricity, gas, water, airline and broadcasting industries, have been sheltered from competition by the government. However, privatization has ended the protection mechanisms and intensified competition at a startling pace.

In relation to deregulation, the legal, airline and accountancy businesses are now required to engage in 'warfare' to survive. Globalization and foreign market trade allow companies to market and supply imported products to new geographical regions, upsetting the current state of affairs in the regions they have just penetrated (West 2001:29).

Periodic economic slowdowns and full recessions intensify competition. When there is an economic upswing, competitors all gain a fair share of the market. However, during downswings, market share can only be gained by impinging on the market share of one's competitors.

All the factors discussed above have therefore contributed to the expansion and development of CI.

\subsection{Aptitude to use CI}

West (2001:30) believes that there is a high understanding of the tactical applications of CI, since it does not require training or experience to calculate a competitor's prices, sales techniques, staffing policies and other similar issues that would create a successful sales playing field. However, Fine (1997:2) comments that what is inadequately developed is the strategic and future use of intelligence, which would be necessary to place a company in a position to defend itself well against threats. Therefore, the aptitude to use CI optimally stimulates the growth of CI.

\subsection{Ability to study competitors}


According to Jaxworks (2007), it is vital for organizations to conduct daily strategic management activities which include the study of competitors. However, Fahey (2006:1) believes that too much emphasis should not be placed on current competitors while the possibility of potential competitors who may enter the market is neglected. Industry newsletters, company Web sites, press articles and employees are a few sources that companies may use to study a competitor since they provide a decent amount of understandable information which may be processed into intelligence after analytical techniques and full analysis have been conducted. This information is readily available and simply requires CI to be applied to make an impact. The only potential problem is the possibility of dealing with information overload during the extraction of information.

\section{Significance of institutionalizing CI}

In the current competitive landscape that includes competitors, the uncertainties of markets, global trends, political impacts and other similar issues, one can clearly notice that the commercial stage is complex and unpredictable, which makes organizations vulnerable to surprises. According to Aware (2002), a handful of organizations function in a monopolized manner and in almost all cases organizations are faced with the situation where competitors offer similar products and services. In such instances, organizations may be viewed as being indulged in 'war', 'fighting' to gain customers at the expense of each other. To win such a 'war', CI may be viewed as being the 'weapon of effect' since it offers organizations the ability to identify:

- Competitors

- Thought processes

- Plans

- Strengths

- Weaknesses

- Where they may be attacked

- Where the risks of attack are too great

- What competitors plan to do next (Aware 2002).

Guyton (1962:84-88) believes that having the above knowledge about competitors and the general business environment would certainly be beneficial. Research has indicated that organizations that practice CI in an established manner have a larger bracket of revenue accumulated as opposed to those companies who do not practice CI. Research also proves that, during a recession, CI can pay off hugely, as reported by SCIP (2006b). In the findings of a March 2002 Trendsetter Barometer survey conducted by PriceWaterhouseCoopers, CEOs valued competitor information as being either 'very' or 'critically' important. These CEOs grew organization revenue by $14,2 \%$ whereas those who did not institutionalize CI only grew revenues by $11,8 \%$. By placing a premium on CI, therefore, one has the ability to outclass peers based on sustained revenue growth, gross margins and a number of other key performance measures.

Clifford Kalb, the former SCIP president and vice president of strategic business analysis at the pharmaceutical firm Merck \& Co. Inc, states that Merck's CI department was responsible for creating a counter strategy to a competitor's imminent product launch that enabled Merck to anticipate and outmanoeuvre the competition on a 30-day notice from the CI department, which resulted in saving approximately \$200 million to the bottom line with an estimated boost to the bottom line of as high as $\$ 400$ million (SCIP 2006). The significance of CI is clearly evident based on the above facts. 


\subsection{Anticipate changes in the marketplace}

It is believed that those organizations that devote their intelligence efforts to sensing adjustments in the business environment will be the least surprised and negatively affected when industry changes take place (Kahaner 1996:23). To enable this, Rothberg (1997:3-11) believes that organizations may anticipate changes in the marketplace by developing competitive scenarios that would assist in preparatory plans for future changes. Ebiz Enable (2006) adds that the identification of threats is a prime feature of CI.

\subsection{Foresee the movements of competitors}

The nature of CI allows organizations with the ability to trace environmental signals that a new competitor might establish its presence on the scene (Kahaner 1996:24). McGonagle and Vella (1999:173) state that knowing the competition is one part of gaining a competitive advantage, and this is dependent on practising CI.

Organizations that are quick to identify the actions of rivals in the marketplace are better positioned to implement tactical decisions that would place them on a higher level than competitors in terms of a competitive advantage (Kahaner 1996:23; MultiQuest Consultants 2004). By implementing CI, organizations have the ability to anticipate competitor movements by gaining constructive analytical information that would ensure competitiveness (Porter 1998:77-90).

\subsection{Enable effective business strategies}

Competitiveness is based on learning and on the aptitude to listen to consumers, suppliers, competitors, industry experts and, most importantly, to one's own employees. The essence of this philosophy is that the competitive environment transmits messages continually about change, trends, prospects, threats and weaknesses. At first these signals may seem ineffective, vague and hidden. However, by paying closer attention to them, their significance for business strategies becomes clear (Farrel 2003). Gilad (1996:17) concurs that such a CI process would have an important influence on the strategic direction of the organization.

\subsection{Learn about political or legislative regulations}

Political and legislative acts have direct effects on organizations. CI departments should as far as possible try to observe how these regulations affect business. On the other hand, and more proactively, CI departments should be able to anticipate new regulations by 'hints' that may appear in the media. It is a known fact that a political crisis in countries affects businesses worldwide (Kahaner 1996:26).

\subsection{Enter new business ventures}

Johnson (2006) affirms that CI assists organizations in selecting new market ventures for existing offerings, revenue streams or other opportunities to grow value for shareholders. Therefore, CI helps organizations to decide whether they should enter a new business, as is well demonstrated by the following example. A Japanese naval architect who designed oil tankers was given the responsibility to design Japan's first tourist ship. The architect and some personnel took cruises around the world in other ships. Before dinner, photographs were taken of the dining arrangements in the restaurants. Once dinner was complete, the number of people present in bars and the swimming pool areas were tallied. Everything that could be noted was entered into a data base, which was then analysed to assist in understanding how a successful cruise-liner should function. All this analysed information 
then led to Japan entering a new line of business (Kahaner 1996:27).

top

\section{CI organizational structure options}

The processes of conducting CI relies on four phases, namely planning, collection, analysis and dissemination. The question is how best to assign responsibilities for executing these phases within the organization. The organizational structure needs to be appropriately suited to do this (Gilad and Gilad 1986:53-60).

A number of uncertainties arise in implementation of CI. For example, it should be decided whether collectors of information and data should also be analysts, whether managers should be involved in carrying out certain tasks or whether there should be corporate involvement in CI.

\subsection{Decentralized approach}

In a decentralized approach, CI operates as a fragmented function carried out by each functional department within the organization, thus servicing each departments' needs exclusively. For example, market research conducts market studies for the sales and marketing department and the research and development (R\&D) department stays abreast of developments that affect their department (Gilad and Gilad 1988:159). A huge benefit of this structure, according to Kahaner (1997:133), is that decentralized systems allow for easier communication of information through dependence on interpersonal networking and spontaneous team building.

\subsection{Centralized approach}

In the sphere of centralized CI, there is one CI unit that services the requests of the entire organization. Large organizations usually opt for this approach (Miller 2000:48). A centralized CI approach begins with the notion that strategic needs are dominant and that the decisions concerning strategy are made by corporate decision makers. Therefore, centralized approaches stand alone and function by relying on information and analytical contributions from the entire organization. Miller (2000:48) extends the view that those working within this unit usually report to a senior corporate executive who has the responsibility for ensuring that the necessary organizational support for the CI process is in place. A centralized CI approach would lessen redundancy and enable data to be assembled and shared in a simpler fashion because all divisions route their information to a single, organizing unit. Commenting on this, Kahaner (1997:133) confirms that, ultimately, this practice improves the synchronization and sharing of data.

Kahaner (1997:133) provides concluding insight into this approach by stating that the storage of information and its dissemination is nevertheless strongly tied to functional or divisional structures and decision making is often attained through committees. Information usually tracks up or down the hierarchies but barely across divisions.

\subsection{Hybrid approach}

The hybrid approach is a combination of centralized and decentralized approaches where the senior executives' needs are the principal thrust in establishing intelligence targets. It is stated that hybrid approaches have a degree of flexibility and are therefore able to deal with operational needs as well. In terms of the collection and analysis of information and the number and type of intelligence products, the hybrid approach is quite uniform across the 


\section{Establishing a CI culture}

For CI to become a successful practice, organizations must enhance a culture within their organization that is capable of promoting the exchange of knowledge and thoughts among individuals and departments (Pole 2000:25-31).

Regrettably, a large number of organizations in contemporary times still look internally (like the old industrial industries where individual departments such as the marketing, engineering or human resources act independently), without sharing information or ideas - whether strategic, tactical or technological. The outcome is that the organization undergoes anguish (Dent 1999:576).

Ghostal and Westney (1991:17-31) state that, to break away from this scenario, there should be a high degree of organizational consciousness of creating a culture of competitiveness. For this to occur, the appropriate atmosphere for CI must be created. This would require continual staff training where ample emphasis must be placed on the significance of CI.

It is believed that even though decision makers are the primary users of CI, the constant gathering of information should be the responsibility of all within the organization (Kahaner (1997:53). However, in the absence of a well established CI mindset to support intelligence and information sharing, it would be difficult to expand intelligence within an organization.

Calof and Viviers (2001:61-67) are of the opinion that suitable education about intelligence seems to be the only way to develop positive mindsets about CI. They add that the most successful technique for stimulating CI within organizations is to conduct training sessions particular to the respective industries.

However, they caution that, for CI training to function correctly, the organization should be equipped with adequate knowledge of CI and the organization's managers particularly, should recognize the value that CI may present to enhance competitiveness by making enhanced decisions. In addition to enhancing a

CI culture, organizations should work on the right CI skills and then develop apt training programmes.

Viviers et al. (2005:576-589) put forth a few vital points regarding the establishment of a CI culture:

- Introduce structural alterations by means of the growth and expansion of integrating mechanisms, for example establishing a central pooling point of information.

- Assign CI co-ordinating officers within the organization.

- Develop an intelligence database.

- Establish a continuous sensitization programme with the goal of informing employees what CI is, what they can and should contribute and exhibiting the value of shared information.

- Discuss CI and the importance of a learning or knowledge-based organization as a recurring item on any meeting's agenda.

- Establish simple codes of ethics that provide guidance to employees about ethical behaviour.

Sewlal (2003) states that a strong intelligence culture is one in which a sizeable number of 
staff members present intelligence on competitors and business trends to the organization. Furthermore, a CI culture occurs where intelligence is always demanded at all levels before decisions are made.

Viviers, Saayman, Calof and Muller (2002:27-37) claim that CI should be incorporated throughout the organization and it should be fixed in and aligned with an organization's infrastructure while being flexible to changes that may occur.

\section{Empirical survey}

\subsection{Methodology}

The purpose of this study was to determine the significance of CI in a mass import retail organization in South Africa. A questionnaire was sent to employees within the organization. A register of employees from the human resources department revealed that there were 183 employees present in the organization. A total of 107 employees from various areas of the organizational structure were randomly selected to represent the entire population. Nachmias and Nachmias (1996:225) confirm that questionnaire surveys are usually anonymous and within this study total anonymity was guaranteed to both the organization and the employees, due to the sensitivity of the issues within the questionnaire. In fact, reference to the term competitive intelligence was strictly excluded. The distributed questionnaire consisted of eight pages with 26 questions. A period of four weeks was allowed for the completion of the questionnaire. Within this period, a number of follow-up procedures were executed to remind individuals of the necessity for completing the questionnaire. It is believed that the timing of follow-up procedures is important as these were conducted on a weekly basis. It is noted by Nachmias and Nachmias (1996:226) that questionnaires are known to have a poor response rate. However, the physical distribution of questionnaires seemed to have had a positive effect and a remarkable response rate of $100 \%$ was attained.

\subsection{Findings}

\subsubsection{Position in organization}

The majority of respondents (34,6\%) were consultants, followed by 31,8\% who were employed on a managerial level or as heads of business units. Executive committee members accounted for $4,7 \%$ whereas $1,9 \%$ represented those on board level. It was noted that $27,1 \%$ of the respondents fell within the 'other' category, namely students, part-time employees, secretaries and personal assistants.

\subsubsection{Environmental scanning}

A total of $51,4 \%$ of the respondents indicated that their organization coped on an average level with regard to changes in the business environment, whereas $48,6 \%$ believed that they coped above average or very well.

Figure 1 depicts that 29\% of respondents monitored the economic environment on a daily basis to gain information on competitors, $17 \%$ on a weekly basis, $21 \%$ on a monthly basis, $11 \%$ on a quarterly basis and $29 \%$ never monitored this field.

Figure 1 Monitoring the external environment 


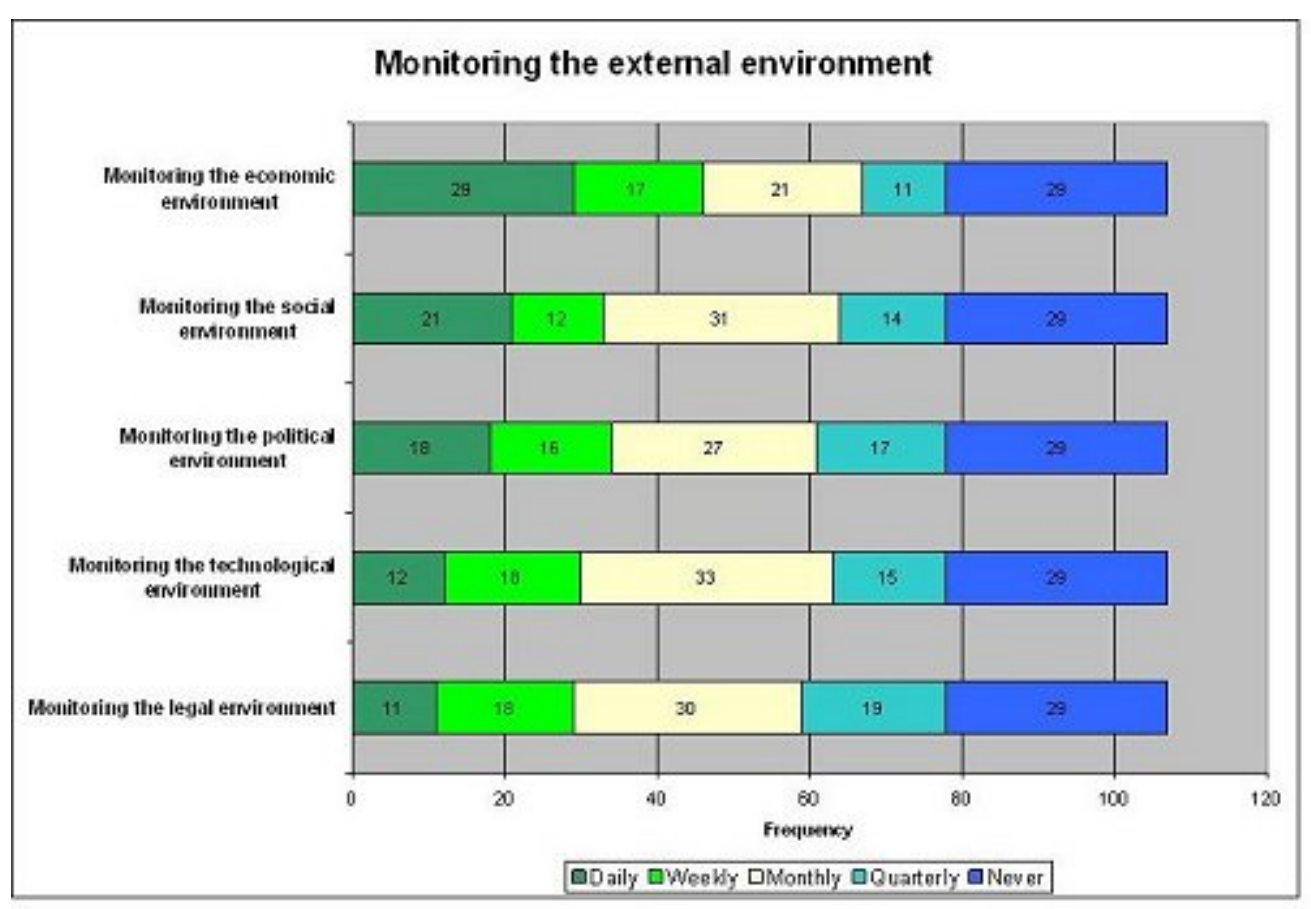

Considering that this organization was in the import or retail industry, it seemed obvious that it would be influenced by the economic environment and it was because of this that the majority of respondents monitored this sphere daily and thus gained information on competitors. Awareness was directed towards being alert to various aspects in the economy such as the exchange rate, interest rate and inflation rate since these factors affected all organizations in the importing industry directly.

In terms of keeping abreast of activities relating to competitors in the social environment, $21 \%$ of respondents stated that they monitored this area on a daily basis, $12 \%$ on a weekly basis, 31\% monthly, $14 \%$ quarterly while $29 \%$ never exercised monitoring activities.

The examination of the social environment therefore seemed to be of importance to this organization and it is assumed that the organization was dedicated to identifying and analysing trends in society, such as social spending patterns and changing tastes and preferences relating to rivals.

The political environment was monitored on a daily basis by $18 \%$ of respondents and $16 \%$ monitor this weekly, $27 \%$ on a monthly basis and $17 \%$ quarterly, while $29 \%$ never conducted such monitoring.

The stability of the political system and issues within this area required attention. However, this organization focused on monitoring it on a monthly basis since political systems did not alter daily and affected the organization as well as competitors to the same extent.

In the sphere of technological monitoring for gathering information on competitors, $12 \%$ examined this area daily, $18 \%$ weekly, 33\% monthly, $15 \%$ quarterly and $29 \%$ did not monitor the technological environment.

The technological environment had to be assessed regularly since this organization had to be updated with the latest products, materials, processes, methods and inventions that may possibly be adopted by rivals as well. It is disappointing to note that most respondents in the organization monitored the technological sphere to gain information on competitors on a monthly basis when it is known that new developments take place daily. This could be an area for improvement. 
Within the legal sphere, 11\% of respondents monitored this daily, 18\% monthly, 30\% monthly, $18 \%$ quarterly and $29 \%$ never kept updated within this environment relating to competitors.

It is crucial for any organization to monitor legislation since regulations have a direct effect of the functioning of this organization and its competitors. It is encouraging to note that the organization exercised such monitoring, albeit mostly on a monthly basis.

Since this organization conducted importing from abroad, it had to monitor the economic, social, political, technological and legal environments both domestically and internationally in the context of competition. Kahaner (1996:26) believes that changes in the above environments must be identified by detecting clues. It is disappointing to discover the large number of respondents who did not monitor the various environments. This may lead to a situation of being uninformed regarding competition.

The organization appeared to understand the importance of environmental scanning (Figure 1). Coping favourably with environmental changes would have allowed this organization to gain a competitive advantage. This trend is aligned to the statement by Kahaner (1996:23), who stated that organizations that focus their efforts on being alert and coping with the environment in which they operate will ultimately be the least surprised and negatively affected by possible changes within the industry.

\subsubsection{Intensity of competition in the business environment}

In assessing the perceived level of competition present in the business environment, 58,9\% of respondents were of the opinion that it was very intense, while $41,1 \%$ believed that competition was intense. None of the respondents claimed that competition is not intense.

Since competition was intense in this organization's environment, it was important that it had measures in place to deal with changes in the environment. This would enhance operations, products and services provided, encourage efficiency and it may be argued that growth along with sustainability may be increased as well (West 2001:29).

\subsubsection{Strategy to manage competitors}

In trying to establish whether there was a strategy in place to manage competitors, $97,2 \%$ of respondents answered in the affirmative while only 2,8\% did not know whether there was a strategy in place for this purpose. This means that this organization was competitor orientated and understood the significance of having a strategy in place to deal with competition. Such a strategy may encourage innovation and alliance with customers, which would lead to a competitive advantage. Gilad (1996:17) concurs with the above and affirms that having a strategy in place would have a positive impact on the strategic direction of an organization.

\subsubsection{Information collection activities related to competitors}

Information collection activities in relation to competitors were mostly conducted on a monthly basis (see Table 1), which accounted for $53,3 \%$ of responses, whereas $40,2 \%$ conducted this on a weekly basis. Only 4,7\% retrieved information on competitors on a daily basis, compared to $1,9 \%$ who never engaged in this activity.

Table 1 Information collection activities

\begin{tabular}{|l|l|c|c|l|l|}
\hline & & Frequency & Percentage & $\begin{array}{l}\text { Valid } \\
\text { percentage }\end{array}$ & $\begin{array}{l}\text { Cumulative } \\
\text { percentage }\end{array}$ \\
\hline & Daily & 5 & 04,7 & 04,7 & 04,7 \\
\cline { 2 - 5 }
\end{tabular}




\begin{tabular}{|l|l|c|c|c|c|}
\multirow{5}{*}{ Valid } & Weekly & 43 & 40,2 & 40,2 & 44,9 \\
\cline { 2 - 6 } & Monthly & 57 & 53,3 & 53,3 & 98,1 \\
\cline { 2 - 6 } & Never & 2 & 01,9 & 01,9 & 100,0 \\
\cline { 2 - 6 } & Total & 107 & 100,0 & 100,0 & \\
\hline
\end{tabular}

The above results indicate that information collection activities were conducted frequently, the bulk of which were performed weekly and monthly. Comparing this with the findings of the study conducted by De Pelsmacker, Muller, Viviers, Saayman, Cuyvers and Jegers (2005:606-620), it is noted that a significant amount of time was attached to the frequent information collection activities. It is noted that information collection activities did take place frequently and it is clear that this organization was competitively minded.

\subsubsection{Information sources used}

According to Figure 2, 53\% of respondents utilized published media as a secondary source of information to assess the competitive environment, closely followed by $51 \%$ who utilized survey summaries. Of the respondents, $50 \%$ claimed that they benefited from making use of Internet sources, 34\% consulted research results and other publications, 28\% of respondents utilized industry analyst reports, $27 \%$ made use of company documents, $22 \%$ claimed that they read market research reports and only $2 \%$ utilized trade journals whereas none of the respondents utilized books or edited reports.

Figure 2 Secondary sources of information consulted

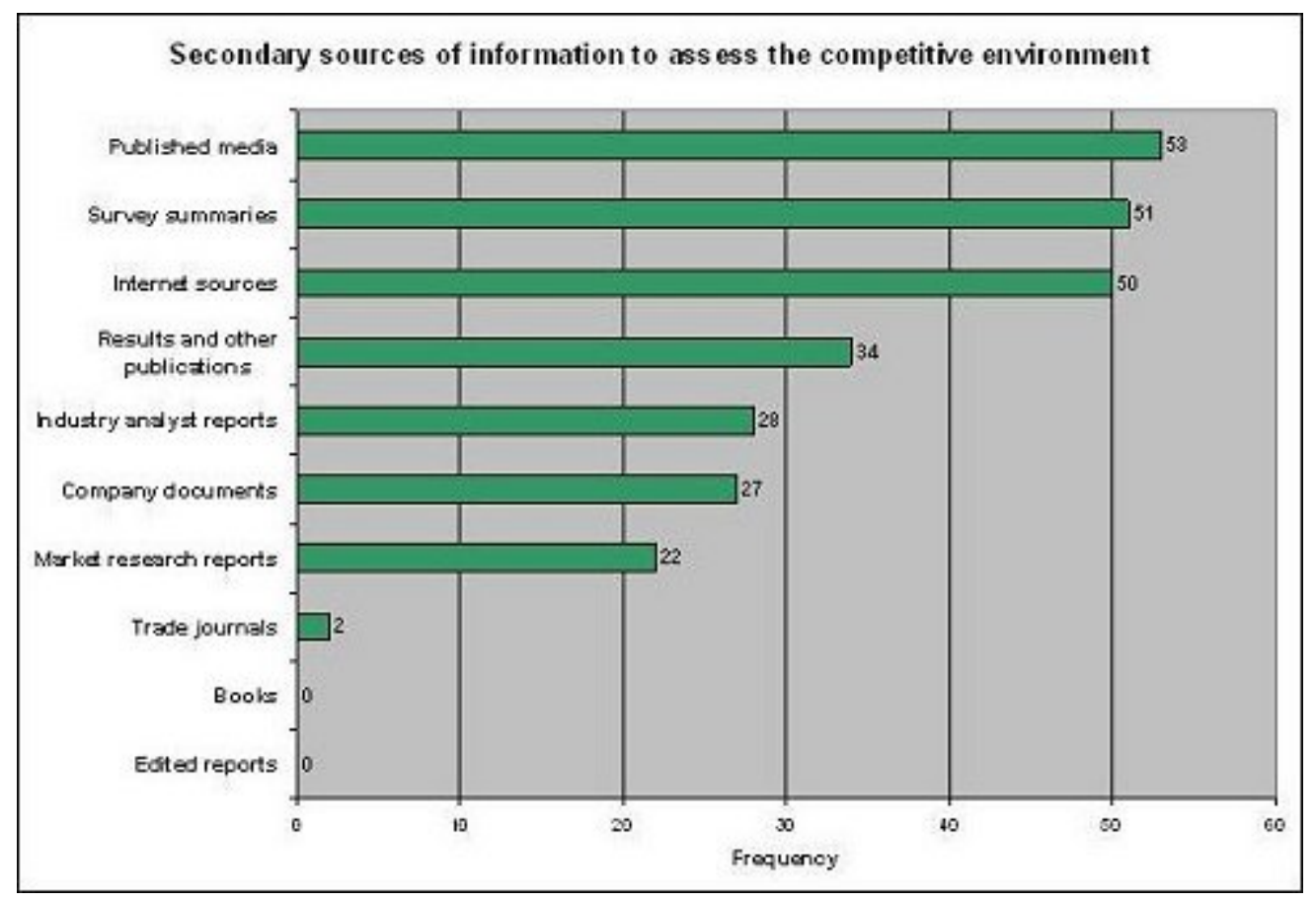

Published media (business journals, trade press, academic and semi-academic publications, industry newsletters and conference papers) was utilized the most since it was assumed that it offers this organization important information on a favourable time scale to assess the competitive environment. The results of the study conducted by De Pelsmacker et al. (2005:606-620) reveal a similarity in that published media is an important source of information for exporters.

Survey summaries were frequently utilized within this organization and it was interpreted that this source of secondary information provided excellent focus on pragmatic occurrences 
in the competitive environment.

The scale at which the Internet was utilized as a secondary source of information, as indicated by respondents, was no surprise since this medium had many advantages such as speed and new information on a plethora of topics available daily. Via the Internet, this organization focused on competitive issues in the import or retail context.

Industry analyst reports, company documents, market research reports and trade journals were not consulted as frequently as the sources mentioned above and the perceived reason for this was that these sources might not have been available and accessible on a regular basis.

Books and edited reports did not seem to provide valuable and regularly updated competitive environmental information.

The above statistics confirm what West (2001:51) states, namely that there is a large amount of emphasis placed on secondary sources as a means of information collection. The benefit, according to McGonale and Vella (1990:59), is that such sources are economical to consult. However, ample time is needed to scan through the information.

With regard to the use of primary sources, Figure 3 shows that $52 \%$ of respondents claimed sales staff to be the most frequent source of primary competitive information, followed $46 \%$ of respondents affirming that customers were an informative source and $43 \%$ stating that staff joining from competitors were of use. Forty-two per cent gained information from suppliers, 36\% revealed that staff attending conferences and seminars were a primary source of information, $30 \%$ believed that employees in competitor organizations might be utilized to extract information, whereas only $26 \%$ of respondents claimed that members of professional trade and industry associations were a source of information. Journals and brokers' analysts were not referred to at all.

Figure 3 Primary sources of information consulted

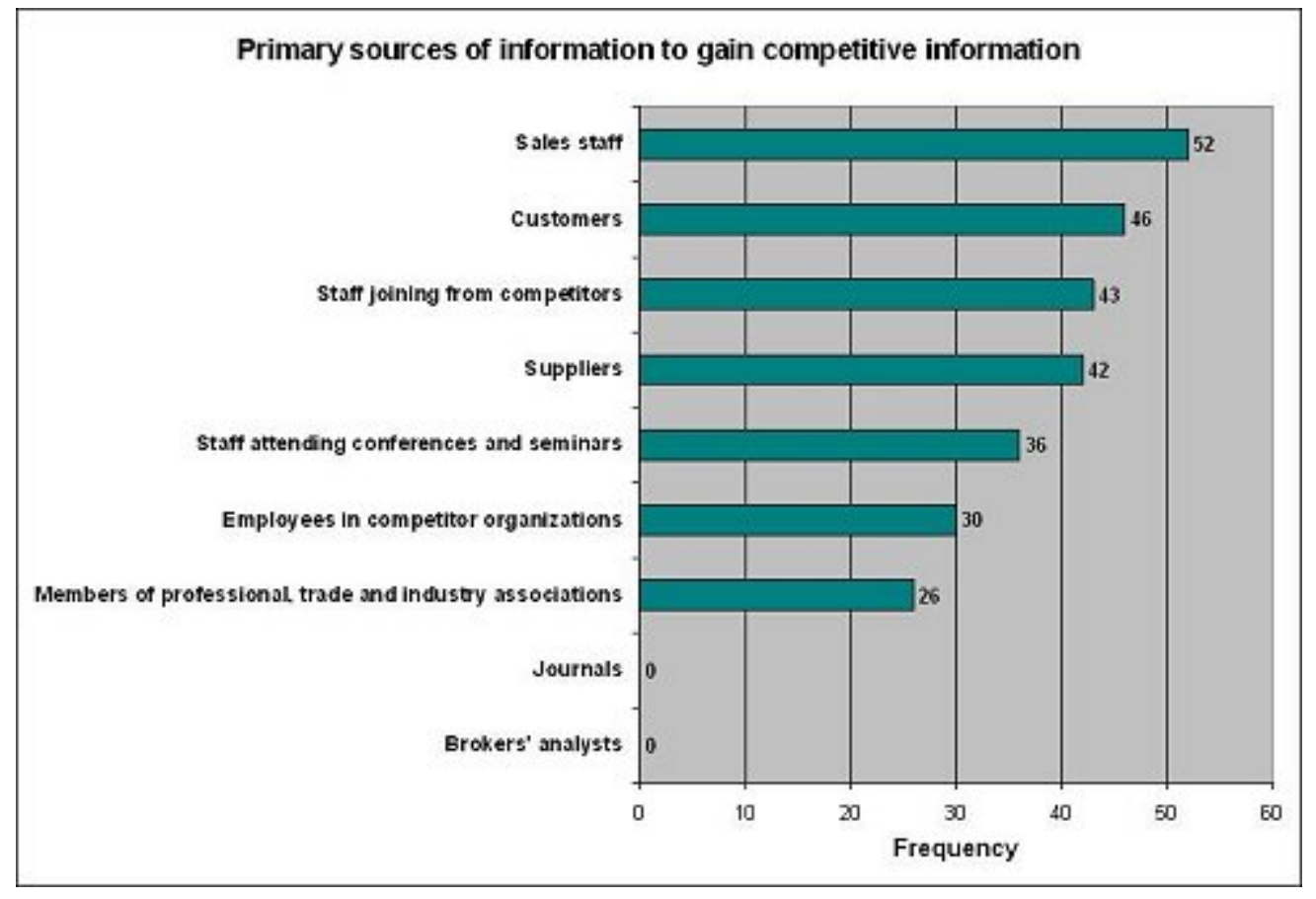

It is clear that this organization utilized sales staff who would listen and observe comments made by customers about competitors, obtain information from competitors' reception areas, 
for instance, be sensitive to the deliveries being made to competitors and also pay attention to industry gossip. Such information would be advantageous and this is confirmed by this organization utilizing this source the most. The sales staff or company staff members, as De Pelsmacker et al. (2005:606-620) state, are also an important source of information for exporters.

It was interesting to note that a large amount of respondents utilized staff members who had been employed in competitor organizations as a source of competitive information. There were a few individuals who had been recruited from rivals who provided valuable information to assist this organization in understanding the strengths and weaknesses of competitors. By understanding these factors, this organization could focus on attaining a competitive advantage through the use of primary sources, a practice that is highly valued according to Klein (2006). West (2001:87), however, asserts that the boundary between ethical and unethical means to gain information must always be respected.

\subsubsection{Analysis of information}

A SWOT analysis is a useful tool to utilize since it may provide CI analysts with a comparison between their organization and competitors' and how the future may be shaped (Kahaner 1996:98). According to Kahaner (1996:24), the ability to be aware of the environment is vital. Four per cent of respondents claimed that they analyse competitors' strengths daily, $12 \%$ analysed this weekly, $38 \%$ on a monthly basis, $20 \%$ quarterly and $33 \%$ never analysed this environment.

In terms of analysing competitors' weaknesses, $4 \%$ of respondents analysed this on a daily basis, $15 \%$ on a weekly basis, $36 \%$ on a monthly basis and $19 \%$ on a quarterly basis, whereas $33 \%$ never analysed the weaknesses of rivals.

Opportunities that competitors may pursue were analysed daily by $7 \%$ of the respondents. Thirteen per cent analysed this weekly and 35\% on a monthly basis, $19 \%$ conducted such analysis quarterly while 33\% never involved themselves in this field of analysis.

\subsubsection{Dissemination of information}

To assess whether products that were disseminated in the organization contained competitive information, $84,1 \%$ of the respondents indicated that there were such products. On the other hand, 8,4\% did not know about these products, compared to 7,5\% who stated that there were no such products disseminated. These products were in the form of e-mails and corporately produced reports relating to competition and presentations. In assigning a rating to the disseminated products in terms of providing competitive insight, 52,7\% indicated that their quality was average in nature, $30,8 \%$ stated that they were good, $14,3 \%$ specified that they were poor, while only $2,2 \%$ rated the products as excellent.

The areas that may threaten competitors were analysed daily by $7 \%$ of respondents, $14 \%$ analysed this on a weekly basis, 34\% analysed this area on a monthly basis, whereas $19 \%$ of respondents analysed this quarterly and 33\% never monitored competitor threats.

In this organization, analysis of competitors mostly took place on a monthly basis and it is clear that this organization understood that they could not only be aware of their environment but they also needed to be well acquainted with competitor strengths, weaknesses, opportunities and threats.

\section{Recommendations}


Based on the findings of the questionnaire results, there are areas that this organization may improve upon.

A large number of respondents did not monitor the business environment or analyse the strengths, weaknesses, opportunities and threats of their organization or those of competitors, which is a major vulnerability. This deficiency could be addressed by dedicated CI personnel who would attend to these tasks upon implementation of a CI function.

Another weakness is that the disseminated CI products were mostly considered to be average in nature and these products were not utilized frequently enough. The recommendation is to assign the creation of these products to the CI function. For CI to function optimally within this organization, it would be necessary to devise a few critical success factors that would have top management involvement. There should be a clear understanding of what is important and required within this organization and there should be proficiency when converting information into intelligence, ensuring that all employees are involved in CI while maintaining ethical standards of CI operation (eCompetitors 2006). From the outset, the complete commitment to CI from the two board members as well as the executive committee members within this organization must be gained and the recommended manner in which this should be done is to demonstrate the benefits of a CI function to these individuals. It would be necessary for a 'champion' to be selected in a highly ranked position within this organization and this 'champion' should be responsible and accountable for the direction and implementation of the CI function. The CI manager should determine the users of CI. In the context of this organization the board members, executive committee members, managers and consultants would most likely be the target group. The exact intelligence needs of these individuals should be ascertained. The products that would be delivered, and resources required for the delivering of these products, should be clearly confirmed by the selected CI manager. It would be vital to implement a CI strategy that would assist in improving the organization's market share in relation to that of competitors. The ultimate outcome would be to achieve a competitive advantage based on this organization's core competencies.

\section{Conclusion}

In this article the value and significance that CI has to offer organizations are discussed as well as a number of key factors which should be considered when embarking on a CI venture. The dynamics of CI are explored to reveal that this business science is the systematic process of planning to gather, analyse and disseminate intelligence relating to the movements of competitors as well as the general business environment to further an organization's goals. It is clear that CI places emphasis on creating knowledge from obtainable information by means of utilizing a systematic process, after which decision makers would be able to take action to realize a competitive advantage.

The objective of this study was to determine the level of importance attached to CI at a mass import retail organization and it was found that there was a relatively high level of importance attached to it. Although there were activities pertaining to CI within this organization, it was recommended that a formal CI function be implemented to achieve optimal competitive performance.

\section{References}

Aware. 2002. Competitive intelligence for business success. [Online]. Available WWW: 
http://www.marketing-intelligence.co.uk (Accessed 13 July 2006).

Calof, J. and Viviers, W. 2001. Creating an intelligence society in South Africa. Africa Insight 31(2):61-67.

Cook, M. and Cook, C. 2000. Competitive intelligence. London: Kogan Press.

De Pelsmacker, P., Muller, M.L., Viviers, W., Saayman, A., Cuyvers, L. and Jegers, M. 2005. Competitive intelligence practices of South African and Belgian exporters. Marketing Intelligence \& Planning 23(6):606-620.

Dent, S. 1999. Partnering intelligence: creating value for your business by building strong alliances. Los Angeles: Davies-Black Publishing.

Ebiz Enable. 2006. Competitive intelligence. Canada: Business Service Centre.

eCompetitors. 2006. Critical success factors. [Online]. Available WWW:

http://www.ecompetitors.com/strategy/corpateplanning/corp_critical_success_factors.htm (Accessed 20 November 2006).

Fahey, L. 2006. Competitor analysis: turning data to insight. London: A \& C Black Publishers.

Farrell, A. 2003. Competitive intelligence - the key to managing external affairs. [Online]. Available WWW: http://www.worksys.com/knowledge.htm (Accessed 6 July 2006).

Fine, N. 1997. Competitive intelligence: an external threat and an internal requirement. [Online]. Available WWW: http://209.85.135.104/search?q=cache:9hG3gIziZkJ:www.protecdata.com/pdfs/CompetitiveIntelligenceArticle.pdf + \%22competitive+intelligence+audit\%22\&hl=en\&ct=clnk\&cd=7 (Accessed 10 May 2007).

Ghoshal, S. and Westney, D. 1991. Organising competitor analysis systems. Strategic Management Journal 12(1):17-31.

Gilad, B. 1996. The art and science of business intelligence analysis. Conneticut: Jai Press.

Gilad, B. and Gilad, T. 1986. Business intelligence - the quiet revolution. Sloan Management Review 27(4):53-60.

Gilad, B. and Gilad, T. 1988. The business intelligence system - a new tool for competitive advantage. New York: Amacon.

Guyton, W. 1962. A guide to gathering marketing intelligence. Industrial Marketing 1 (1):84-88.

Hambrick, D. and Fredrickson, J. 2005. Are you sure you have a strategy? Academy of Management Executive 19(4):48-59.

Havenga, J. and Botha, D. 2003. Competitive intelligence in a knowledge-based organization. Management Today 19(6):26-35.

Hitt, M., Ireland, R. and Hoskisson, R. 2000. Case notes for strategic management: 
competitiveness and globalization. Annotated Textbook 4(1):208.

Jaxworks. 2007. Strategic action planning for the small business. [Online]. Available WWW: http://www.jaxworks.com/strategy2.htm (Accessed 2 February 2007).

Johnson, A. 2006. The top 12 priorities for competitive intelligence. [Online]. Available WWW: http://www.aurorawdc.com/arj_cics_priorities.htm. (Accessed 4 July 2006).

Kahaner, L. 1996. Competitive intelligence: from black ops to boardrooms. How businesses gather, analyze, and use information to succeed in the global marketplace. New York: Simon \& Schuster.

Kahaner, L. 1997. Competitive intelligence. New York: Touchstone.

Klein, C. 2006. Finding business information on US corporations. [Online]. Available WWW: http://www.amconmarketing.com/html/articles-info.html. (Accessed 10 July 2006).

McGonale, J. and Vella, C. 1990. Outsmarting the competition: practical approaches to finding and using competitive information. Naperville: Sourcebooks.

Miller, J. 2000. Millennium intelligence: understanding and conducting competitive intelligence in the digital age. New York: Cyberage Books.

MultiQuest Consultants. 2004. Our knowledge forms a little idea in a great ocean of data. [Online]. Available WWW: http://www.mqcinc.com. (Accessed 13 August 2006).

Nachmias, C. and Nachmias, D. 1996. Research methods in the social sciences. London: Arnold.

Pole, J. 2000. Competitive intelligence as a construct for organizational change. Competitive Intelligence Review 11(4):25-31.

Porter, M. 1998. Clusters and the new economics of competition. Harvard Business Review 77(6):77-90.

Rothberg, H. 1997. Fortifying competitive intelligence systems with shadow teams. Society of Competitive Intelligence Professionals 3(1):3-11.

SCIP. 2006. Society of competitive intelligence professionals. [Online]. Available WWW: http://www.scip.com. (Accessed 6 June 2006).

Sewlal, R. 2003. Effectiveness of the Web as a competitive intelligence tool. South African Journal of Information Management 6(1). [Online]. Available WWW:

http://www.sajim.co.za/default.asp?to=peer2vol6nr1. (Accessed 10 June 2006).

Tyson, K. 1995. Competitive intelligence management.Competitive Intelligence Review 6 (4):14-21.

Viviers, W., Saayman, A., Calof, J. and Muller, M.L. 2002. Competitive intelligence practices: a South African study. South African Journal for Business Management 33(3):2737.

Viviers, W., Saayman, A. and Muller, M.L. 2005. Enhancing a competitive intelligence 
culture in South Africa. International Journal of Social Economics 32(7):576-589.

West, C. 2001. Competitive intelligence. New York: Palgrave.

\section{West, C. 2001. Competitive intelligence. New York: Palgrave.}

ISSN 1560-683X

Published by InterWord Communications for Department of Information and Knowledge Management, University of Johannesburg 